\title{
Retaining Science Teachers in Rural School Districts: Examining the Unintended Consequences of the No Child Left Behind Act
}

\author{
James R. Harrington \\ School of Economic, Political \& Policy Sciences, University of Texas at Dallas \\ 800 W. Campbell Rd. GR. 31 Richardson, Texas 75080, United States \\ Tel: 1-972-883-3513 E-mail: james.harrington@utdallas.edu
}

$\begin{array}{lr}\text { Received: February 7, } 2017 & \text { Accepted: February 21, } 2017 \quad \text { Published: February 28, } 2017 \\ \text { doi:10.5296/gjes.v3i1.10698 } & \text { URL: http://dx.doi.org/10.5296/gjes.v3i1.10698 }\end{array}$

\begin{abstract}
Previous case studies find that rural school districts have been struggling to recruit and retain high quality teachers after the implementation of the No Child Left Behind Act (NCLB). Scholars and practitioners argue this labor market problem is even more dire in hard-to-recruit subject areas such as science and mathematics. While there is ample antidotal evidence, there is still no empirical studies that have leveraged a longitudinal dataset to estimate the impact of NCLB on teacher retention in rural school districts. To better examine the intended and unintended consequences of NCLB, this study leverages a longitudinal statewide panel dataset at the district level to examine the capability of rural school districts to recruit and retain science teachers. We find that rural school districts near metropolitan or micropolitan statistical areas employed fewer science teachers after the NCLB passage, while remote rural school districts did not experience a decline. This article highlights that rural school districts have differential effects on their ability to recruit and retain science teachers based on their proximity to urban areas.
\end{abstract}

Keywords: No child left behind, Rural teachers, Science teachers, Hard-to-Recruit teachers 


\section{Introduction}

While the education policy literature has extensively examined the intended and unintended consequences of the No Child Left Behind Act (NCLB) in urban school districts (Jacob, 2005; Neal \& Schanzenbach, 2010; Roderick \& Nagaoka, 2005), researchers have largely overlooked the impact of NCLB on rural school districts (Monk, 2007). Previous case studies find that high-quality teacher provisions in the NCLB Act created unique challenges for rural school districts to recruit and retain teachers. Monk (2007) finds several challenges facing rural school districts include but are not limited to: (1) teachers often teach out of their core certified field; (2) rural school districts lack economies of scale in offering more specialized teaching areas; and (3) rural school districts may reside in "remote" locations making it difficult to attract applicants without connections to the area.

Based on these contextual factors, scholars argue that rural school districts face challenges in recruiting and retaining high quality teachers especially in difficult-to-recruit subject areas such as science and mathematics. While case studies find rural school districts face challenging labor market conditions, the current literature lacks empirical studies that examine the link between NCLB and teacher labor markets in rural school districts. To contribute to the literature, this study leverages a longitudinal dataset to explore the impact of NCLB's high quality teacher provision on employment numbers of science teachers employed in rural school districts.

Based on our results, we find that requiring rural school districts to comply with the NCLB "high quality" standards decreased the number of science teachers employed in fringe rural areas (i.e., rural areas within a Core Based Statistical Area), which validates the case study findings and anecdotal evidence that rural school districts are having problems recruiting and retaining specialized teachers. Contrarily, we find that remote rural schools (i.e. not in a Core Based Statistical Area) do not experience a decline in the number of science teachers after the passage of NCLB. This research partially supports previous qualitative case studies by finding an effect in fringe rural areas but not in remote areas; yet illustrating the fact different types of rural school districts face different constraints.

\section{Literature Review}

\subsection{No Child Left Behind Act}

Historically, the U.S. education system has decentralized the control and operation of public schools to individual and autonomous districts with the federal government having minimal formalized authority in public education (Bierlein, 1993). Under this system, local school districts, and to some degree state governments, were involved in the direct delivery of goods and services in the public education sector (Salamon, 2002). To overcome a perceived collective action problem of failing schools across the nation, the No Child Left Behind Act (NCLB) was a federal intervention that set higher standards and required greater accountability to improve education service delivery.

One of the key purposes of the NCLB was to require that teachers be certified and designated as "a high quality" teacher. To be highly qualified and certified under NCLB, teachers must: 
(1) obtain a content area bachelor's degree in the subject taught, (2) obtain a full state certification or licensure, and (3) obtain proof of content knowledge for each subject taught. Previous studies, especially work by Darling-Hammond (1999), have found that "high quality" teachers are one of the most important factors to improve student achievement. Furthermore, the effectiveness of a high-quality teacher has an enduring effect on students as they progress in their educational careers (Darling-Hammond, 1999).

After the passage of the high-quality teacher provisions, rural school districts faced additional hurdles and pressures to recruit and retain teachers. Also, administrators had to ensure their current workforce received the proper certifications to be classified as high quality. Adding complexity to the issue, it is a common practice for rural teachers to teach in more than one academic subject to provide a rich and diverse curriculum for students. For some rural school districts, the U.S. Department of Education offered a rural flexibility program for sparsely-populated districts as a means of delaying compliance; thus at least acknowledging some of the unique contextual factors facing rural school districts. As Eppley (2009) notes, "rural and small schools that are unable to meet the demands of NCLB may have no choice but to consolidate (9)."

\subsection{Challenges Facing Rural School Districts in NCLB Era}

Scholars such as Monk (2007) argue that the federal government's definition of highly qualified teachers creates problems for rural school districts, because rural teachers often teach in out-of-area subjects (Jimerson, 2005; Eppley, 2009). For this reason, rural school districts tend to have difficulties recruiting and retaining teachers in specialized areas such as foreign languages, mathematics, science, and special education (Reeves, 2003; Brownell, Bishop, \& Sindelar, 2005; Erickson, Noonan, \& McCall, 2012; Howley, Rhodes, \& Beall, 2009; Opuda, 2003). For out-of-area applicants, rural school districts struggle to compete with their urban or suburban counterparts based on various factors such as amenities, salaries, teaching demands, and opportunities.

As Collins (1999) notes, it is challenging to recruit new teachers into rural areas, because these school districts are in geographically isolated areas without many amenities. Rural teachers must travel further for shopping, entertainment, and cultural events. Also, compounding issues with recruitment, the salaries for teachers in rural school districts are considerably lower (Reeves, 2003). Often, rural school districts justify the lower salaries because the housing market tends to be less expensive in these areas. Unfortunately, Reeves (2003) argues that teachers who are not from the area are not being enticed by lower housing values.

Furthermore, teachers in rural school districts maybe placed under greater pressures than their suburban counterparts, because it is common for teachers to teach in out-of-field areas (Reeves, 2003). Out-of-field teaching is an important issue for many rural teachers, because high quality teacher provisions require them to be certified to teach all their classes. This might require rural teachers to take more university classes and participate in more professional development to remain certified, but given the remote location of rural school districts, it may be challenging for teachers to attend university courses. This inconvenience 
is yet another disincentive for teachers to serve in rural school districts.

To overcome these issues, some rural communities provide bonuses or other incentives to attract highly qualified teachers to their school districts, but most rural school districts often lack the funding to support such programs (Beesley, Atwill, Blair, \& Barley, 2010; Rosenberg, Christianson, \& Angus, 2015). Alternatively, Barton (2003) finds evidence from her qualitative case study that rural districts develop creative strategies to handle issues created by NCLB policy. For example, three rural school districts in Idaho shared a teacher, because they were unable to find one that met the quality provisions to serve as a full-time employee. Yet these issues of recruiting and retaining a high-quality teacher become more pressing when rural school districts try to recruit and retain science teachers.

\subsection{Science Teachers in Rural School Districts}

Since the 1980s, scholars such as Levin (1985) and Rumberger (1987) find a shortage of mathematics and science teachers. A more recent study by Ingersoll (2003) finds that science teachers are more likely to leave their teaching position, because they are unsatisfied with their pay. Additionally, science teachers may have more technical skills, which may be more marketable to other industries. In the rural context, Collins (1999) finds rural school districts face challenges recruiting and retaining in specialized subject areas. After a rural school district recruits a high-quality science teacher, that teacher may be under a lot of pressure to teach a wide array of science classes to cover all the needs of the school district (Monk, 2007).

Yet, it is important to differentiate between the different types of rural areas (i.e., remote rural or fringe rural). As the Core Based Statistics Area (CBSA) recognizes, not all rural communities are created equal, nor should we assume that all types of rural areas face similar types of pressures to recruit and retain high quality teachers. Particularly, one of the key factors for recruiting teachers is the proximity to a core based statistical area (e.g., areas near a population center). Potentially, in rural school districts near a larger community, science teachers may have more opportunities to work for other types of school districts and potentially industry. Thus, given a greater supply of opportunities, school districts will find it challenging to retain an adequate number of science teachers in these school districts.

$\mathrm{H}_{1}$ : Rural school districts in fringe areas (within CBSA) will have less science teachers after the implementation of NCLB.

Alternatively, rural school districts in more remote areas were already running at minimum staff levels before NCLB. These types of schools tend to be significantly smaller, and it may not be uncommon to only have a few science teachers in the entire school district. For this reason, these schools will undoubtedly have a harder time recruiting and retaining science teachers, but these schools are already running at an absolute minimum level.

$\mathrm{H}_{2}$ : Rural school districts in remote locations will not experience a drop in the number of science teachers after the implementation of NCLB.

Overall, there is a lot of evidence from case studies and interviews about the challenges 
facing rural school districts in the post-NCLB era, but no studies have systematically examined a panel dataset to empirically test if NCLB has affected the number of science teachers employed in rural school districts.

\section{Data and Methods}

To better understand the consequences of NCLB on retaining science teachers in rural areas, this study leverages a longitudinal panel dataset. The dataset has two main components: (1) Staffing data from the Missouri Department of Elementary and Secondary Education, and (2) district level characteristics from the National Center for Education Statistics. The dataset is constructed at the school district level. There are approximately 470 school districts in the state. The state of Missouri is a large Midwestern state with two major metropolitan areas: Kansas City and St. Louis. It has several mid-size cities such as Columbia, Joplin, St. Joseph, and Springfield. The state of Missouri also has hundreds of small rural school districts.

Staffing Data. Public school districts are required to report each year on all teachers to the Department of Elementary and Secondary Education. For each teacher, districts will report information about course and assignment, teaching certifications, and educational background level. Using this data, we can count the number of science teachers and the number of FTEs employed in each school district. The dataset is compiled at the district level.

District-Level Characteristics. The National Center for Education Statistics compiles district and school level data. The district level characteristics are used as key control variables for our model. The control variables include district size, the percent of students in the school who are nonwhite, and the percent of students who are eligible to receive free or reduced price lunch (i.e., a measure of poverty). Controlling for school characteristics helps to eliminate different kinds of work environments.

Dependent Variable. The dependent variable is the number of science teachers in a school district. For the counts, the following assignment codes for teachers were included: biology, botany, chemistry, earth science, ecology, geology, life science, physical science, physics, physiology and anatomy, general science, and zoology. Additionally, to factor both full-time and part-time employees, FTE was calculated. The total science-related FTE reflects how many hours they have devoted to these specialized subjects.

\section{Results}

\subsection{Descriptive Statistics}

Regarding rural areas within a CBSA, the number of science teachers significantly declines after the implementation of NCLB (see Figure 1). Rural areas within a CBSA are defined by the Census Bureau. Before NCLB, these school districts within a CBSA had an average of 14 teachers in the school district, but this number dropped to 12 teachers and remains constant after the policy change. This suggests that these rural school districts within a CBSA are retaining less science teachers in their districts.

School districts in rural areas outside a Core Based Statistical Area (CBSA) have 


\section{Ml Macrothink}

Global Journal of Educational Studies

ISSN 2377-3936

2017, Vol. 3, No. 1

approximately four teachers on average (See Figure 1). A rural area outside a CBSA is defined as "any incorporated place, Census designated place, or non-place territory not within a CBSA and defined as rural by the Census Bureau." Based on the time trend, the average number of teachers does not significantly change before or after NCLB policy. This is inconsistent with previous qualitative findings, but the results are very plausible. These rural schools in remote areas only have four teachers on average in the entire district, so if they lose just one teacher, the superintendent is under serious pressure to find a replacement. For these remote rural districts, it is completely unacceptable not to replace a science teacher in the district.

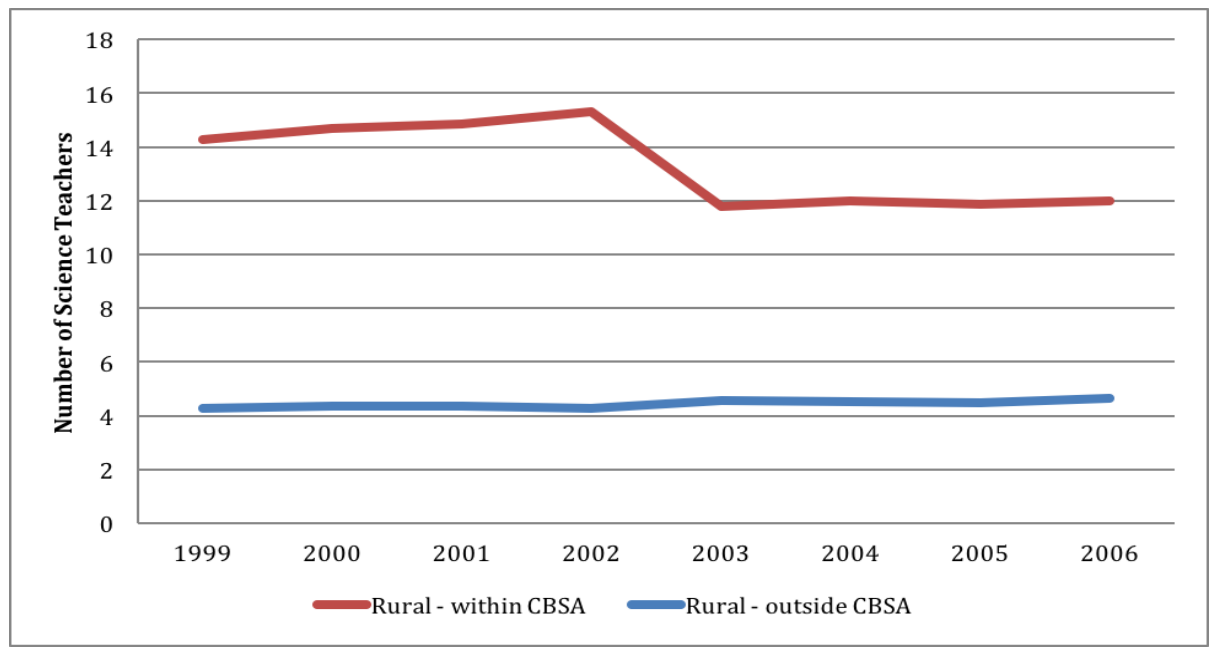

Figure 1. Average number of science teachers in rural areas

\subsection{Regression Models}

To examine the impact of NCLB on rural teacher labor markets, this study includes all Missouri school districts from 1992 to 2010. The model estimates the number of science teachers as a function of the NCLB policy change (NCLB), Rural within a CBSA (Rural), an interaction of $\mathrm{NCLB}^{*}$ Rural, and the characteristics of the district $(D)$ as shown in equation (1):

$$
\text { \# Science Teachers } \text { jt }=N C L B_{j t} \delta+\operatorname{Rural}_{j t} \alpha+N C L B^{*} \operatorname{Rural}_{j t} \lambda+D_{j t} \theta+\gamma_{t}
$$

where $j$ indexes school districts, and $t$ indexes time in years.

The dependent variables are either FTE of science teachers or the number of science teachers itself. In some models, we also include district fixed effects, thereby dropping any coincident time-invariant characteristics. Estimates are derived from using ordinary least squares, with standard errors clustered at the district and year level to consider the fact that we have multiple observations of the same district over time with an autoregressive model; thereby handling any serial correlation issues.

Our regression analysis examines the rural school districts within a CBSA. Rural school 
districts may have several part-time teachers in the district, which may artificially increase the number of teachers. To control for this problem, we measure the number of teachers by FTE. Thus, if a teacher only teaches half the school day; then he or she will only count as a .5 FTE.

The main effect suggests that the number of science teachers has increased after the NCLB policy (Table 1, Models 1 and 2). To examine the effect of NCLB on rural areas, we created an interaction variable between the NCLB policy intervention and being in a rural school within a CBSA area. Consistent with our hypothesis, we find that rural schools within a CBSA have fewer FTE positions in science after NCLB $(\beta=-.727)$ after controlling for various observable characteristics of the district.

Also, to be more rigorous, we included a district level fixed effect to control for time invariant characteristics (Table 1, Model 3 and 4). The major problem is that locale (i.e., being rural) is predominantly a time-invariant characteristic as well. While not ideal, this serves as another robustness check of the OLS model. Consistent with the OLS regression, we find that the NCLB-rural interaction is still negative (Table 1, Model 3 and 4). This suggests that rural schools within a CBSA area have fewer science teachers controlling for various observable district level characteristics and unobservable time-invariant characteristics at the district and year level.

Table 1. Regression for science teachers within a fringe rural area (within a CBSA)

\begin{tabular}{|c|c|c|c|c|}
\hline & $\begin{array}{l}\text { (1) } \\
\text { Science Teachers by } \\
\text { FTE }\end{array}$ & $\begin{array}{c}(2) \\
\text { \# of Science } \\
\text { Teachers } \\
\end{array}$ & $\begin{array}{c}\text { (3) } \\
\text { \# Science Teachers } \\
\text { by FTE }\end{array}$ & $\begin{array}{c}(4) \\
\text { \# of Science } \\
\text { Teachers } \\
\end{array}$ \\
\hline Rural within CBSA & $\begin{array}{c}0.302 \\
(0.189)\end{array}$ & $\begin{array}{c}0.333^{*} \\
(0.2)\end{array}$ & $\begin{array}{c}1.043 * * * \\
(0.148)\end{array}$ & $\begin{array}{c}1.100 * * * \\
(0.240)\end{array}$ \\
\hline NCLB & $\begin{array}{c}0.609 * * * \\
(0.0774)\end{array}$ & $\begin{array}{c}0.662 * * * \\
(0.0817)\end{array}$ & $\begin{array}{c}0.537 * * * \\
(0.0568)\end{array}$ & $\begin{array}{c}0.597 * * * \\
(0.122)\end{array}$ \\
\hline Rural within CBSA * NCLB & $\begin{array}{c}-0.727 * * * \\
(0.243)\end{array}$ & $\begin{array}{c}-0.792 * * * \\
(0.257)\end{array}$ & $\begin{array}{c}-0.855^{* * *} \\
(0.177)\end{array}$ & $\begin{array}{c}-0.960 * * * \\
(0.246)\end{array}$ \\
\hline District - \% Minority & $\begin{array}{c}-1.288 * * * \\
(0.257)\end{array}$ & $\begin{array}{c}-1.663 * * * \\
(0.271)\end{array}$ & $\begin{array}{l}-0.105 \\
(0.497)\end{array}$ & $\begin{array}{l}-0.377 \\
(1.248)\end{array}$ \\
\hline District - \% Free Lunch & $\begin{array}{l}-35.99 \\
(29.92)\end{array}$ & $\begin{array}{l}-50.39 \\
(31.58)\end{array}$ & $\begin{array}{l}-46.62 \\
(35.25)\end{array}$ & $\begin{array}{c}-66.86 * * \\
(32.20)\end{array}$ \\
\hline District - Total \# of Students & $\begin{array}{c}0.00374 * * * \\
(1.04 \mathrm{e}-05)\end{array}$ & $\begin{array}{c}0.00382 * * * \\
(0.000011)\end{array}$ & $\begin{array}{c}0.00365^{* * * *} \\
(2.52 \mathrm{e}-05)\end{array}$ & $\begin{array}{c}0.00373 * * * \\
(0.000199)\end{array}$ \\
\hline Constant & $\begin{array}{c}0.990 * * * \\
(0.0560)\end{array}$ & $\begin{array}{c}1.339 * * * \\
(0.0591)\end{array}$ & $\begin{array}{c}0.981 * * * \\
(0.119)\end{array}$ & $\begin{array}{c}1.333 * * * \\
(0.263)\end{array}$ \\
\hline District Level Fixed Effect Included? & No & No & Yes & Yes \\
\hline Observations & 8,700 & 8700 & 8700 & 8,700 \\
\hline R-squared & 0.950 & 0.947 & 0.9463 & 0.9497 \\
\hline
\end{tabular}

Note. Standard errors in parentheses $* * * \mathrm{p}<0.01, * * \mathrm{p}<0.05, * \mathrm{p}<0.1 ; *$ CBSA- Core-based Statistical Area. 


\section{Conclusion}

Consistent with qualitative studies, this study finds that NCLB has a negative effect on the number of specialized teachers in rural schools within a CBSA (Reeves, 2003; Monk, 2007). Scholars argue that rural schools are unable to recruit and retain these specialized teachers to be in remote communities (Monk, 2007). Based on our study, we do not find evidence that the number of science teachers decreases in rural areas outside a CBSA (see Figure 1). These remote areas may only have three or four science teachers in the entire district. If they lose a chemistry teacher, they must find a replacement or the students will not receive a class in a core area. Not offering a chemistry class to college-bound students is unacceptable, so these rural superintendents are under greater pressures to find a replacement by either giving out incentives or networking with programs that help find specialized teachers in hard-to-staff schools (Monk, 2007). In contrast, we find that the number of specialized teachers is declining in rural areas around a CBSA. We expect that these schools might have approximately 12 science teachers in the entire district. So, if they are unable to find a new teacher, they will develop an internal solution such as using a smaller workforce. They can re-assign teaching assignments or increase class sizes to account for two fewer science teachers. But we might be concerned that fewer science teachers may negatively affect students.

The main contribution of this study was to examine the impact of NCLB on retaining science teachers in rural school districts. As noted, Monk (2007) argues that this policy creates difficulties for rural school districts. Prior research has found that rural school districts before this policy were already having difficulties recruiting and retaining teachers in specialized areas such as foreign languages, mathematics, science, and special education (Reeves, 2003; Brownell, Bishop, \& Sindelar, 2005; Erickson, Noonan, \& McCall, 2012; Howley, Rhodes, \& Beall, 2009; Opuda, 2003). While most of the prior literature has been based on qualitative interviews, this study leverages a district level panel dataset to examine the impact of NCLB on teacher retention in rural school districts. Overall, this empirical study supports the prior research that rural school districts are struggling with recruitment in specialized areas. However, this study finds that the number of science teachers remained unchanged in remote school districts, which contradicts some of the qualitative research. In this study, we argue these schools are operating at minimum levels already and cannot practically operate with fewer teachers. However, it is important to note that while the average numbers are unaffected, the data limitations of the study may not capture the struggles facing these districts.

Regarding the limitations, this study only uses the numerical count and FTE of science teachers in school districts across the state. The major limitation of this study is the use of district level data. When examining labor markets using more macro level data, it is impossible to examine some of the nuances. While we do not find an impact for remote rural school districts using district level data, this does not mean these schools are not struggling with retaining highly qualified science teachers. Using district level data, it is impossible to observe if a science teacher in a remote rural area is teaching in multiple school districts in various counties as suggested by prior qualitative research (Barton, 2003). Additionally, this 
study does not examine the impact NCLB has on teacher experience levels and turnover rates, so we are not able to examine if more unexperienced teachers are working in rural areas and if they have a higher propensity to turnover after a few years of service.

To better explain the results, future research should examine if teachers are "pulled" into suburban school districts from rural ones. These fringe rural areas must compete with suburban areas or other central cities. Thus, the supply and demand characteristics of the urban and suburban schools are out-competing the fringe rural areas; thereby making the fringe rural areas have the supply problem. To examine the causes in more detail, future research should examine the mobility of teachers before and after NCLB using individual-level data. Furthermore, future research should try to better operationalize how many school districts are actively recruiting or searching for specialized teachers. It would be beneficial to collect data on the number of applications received, what kind of qualifications these individuals have, and how many people they are successfully able to recruit. More insight on the recruitment process of teachers in rural school districts is needed.

\section{References}

Barton, R. (2003). Challenges and opportunities of NCLB for small, rural, and isolated schools. Northwest Regional Educational Lab., Portland, Or.

Beesley, A. D., Atwill, K., Blair, P., \& Barley, Z. A. (2010). Strategies for Recruitment and Retention of Secondary Teachers in Central US Rural Schools. Rural Educator, 31(2).

Bierlein, L. A. (1993). Controversial Issues in Educational Policy. Newbury Park: SAGE Publications, Inc.

Brownell, M. T., Bishop, A. M., \& Sindelar, P. T. (2005). NCLB and the demand for highly qualified teachers: Challenges and solutions for rural schools. Rural Special Education Quarterly, 24(1), 9.

Collins, T. (1999). Attracting and retaining teachers in rural areas. Charlestown, Wv: ERIC Clearinghouse on Rural and Small Schools.

Darling-Hammond, L. (1999). Teaching quality and student achievement: A review of state policy evidence. Seattle: University of Washington, Center for the Study of Teaching and Policy.

Erickson, A. S. G., Noonan, P. M., \& McCall, Z. (2012). Effectiveness of online professional development for rural special educators. Rural Special Education Quarterly, 31(1), 22.

Eppley, K. (2009). Rural schools and the highly qualified teacher provision of No Child Left Behind: A critical policy analysis. Journal of Research in Rural Education (Online), 24(4), 1.

Howley, A., Rhodes, M., \& Beall, J. (2009). Challenges facing rural schools: Implications for gifted students. Journal for the Education of the Gifted, 32(4), 515-536.

Ingersoll, R. M. (2003). Turnover and shortages among science and mathematics teachers in the United States. Science Teacher Retention: Mentoring and Renewal, 1-12.

Jacob, B. A. (2005). Accountability, incentives and behavior: The impact of high-stakes 
testing in the Chicago Public Schools. Journal of Public Economics, 89(5), 761-796. http://dx.doi.org/10.1016/j.jpubeco.2004.08.004

Jimerson, L. (2005). Placism in NCLB-How rural children are left behind. Equity \& Excellence in Education, 38(3), 211-219.

Levin, H. M. (1985). Solving the shortage of mathematics and science teachers. Educational Evaluation and Policy Analysis, 7(4), 371-382.

Neal, D., \& Schanzenbach, D. W. (2010). Left behind by design: Proficiency counts and test-based accountability. The Review of Economics and Statistics, 92(2), 263-283.

Monk, D. H. (2007). Recruiting and retaining high-quality teachers in rural areas. The Future of Children, 17(1), 155-174.

Opuda, M. J. (2003). NCLB-A threat or a challenge to public education? A reply to Edmondson and Shannon. Journal of Research in Rural Education, 18(1), 35-38.

Reeves, C. (2003). Implementing the NCLB Act: Implications for rural schools and districts. Washington, DC: North Central Regional Educational Laboratory (NCREL).

Roderick, M., \& Nagaoka, J. (2005). Retention under Chicago's high-stakes testing program: Helpful, harmful, or harmless? Educational Evaluation and Policy Analysis, 27(4), 309-340.

Rosenberg, L., Christianson, M. D., \& Hague Angus, M. (2015). Improvement efforts in rural schools: Experiences of nine schools receiving School Improvement Grants. Peabody Journal of Education, 90(2), 194-210. http://dx.doi.org/10.1080/0161956X.2015.1022109

Rumberger, R. W. (1987). The impact of salary differentials on teacher shortages and turnover: The case of mathematics and science teachers. Economics of Education Review, 6(4), 389-399. http://dx.doi.org/10.1016/0272-7757(87)90022-7

Salamon, L. M. (2002). The Tools of Government: A Guide to the New Governance. New York: Oxford.

Sanders, W. L., \& Rivers, J. C. (1996). Cumulative and residual effects of teachers on future student academic achievement. Tennessee Value-Added Assessment System (TVAAS).

U.S. Department of Education. (2004). New No Child Left Behind flexibility: Highly qualified teachers. Retrieved from htto://www.ed.gov/nclb/methods/teachers/hqtflexibility.html

U.S. Department of Education. (2008). A summary of highly qualified teacher data. Retrieved from http://www.ed.gov/programs/teacherqual/briefing-on- 2006-07-hqt-data.doc

\section{Copyright Disclaimer}

Copyright for this article is retained by the author(s), with first publication rights granted to the journal.

This is an open-access article distributed under the terms and conditions of the Creative Commons Attribution license (http://creativecommons.org/licenses/by/3.0/). 